\title{
The Effect of Using COAP Protocol on Reducing Energy Consumption in Smart Houses (Case Study: Uromieh Culture House)
}

KamelyaDehghaniKohnehshahri

Department of Management Post Graduate Education, Farabi Institute of Higher Education, Karaj, Iran dehghani.mit95@gmail.com

Mohammad Hasan Kargar

Department of Management Post Graduate Education, Farabi Institute of Higher Education, Karaj, Iran Email: mhkargar@gmail.com

Fatemeh Soleimani-Roozbahani ${ }^{1}$

Department of Information Technology Management, Islamic Azad University, Science \& Research Branch of Tehran, Iran

fatemeh.solaymani@srbiau.ac.ir

1. Corresponding author ABSTRACT-

Over the past few years, protocols, implementations, and optimal uses and the use of internet of things have grown dramatically. Among the communication protocols, the COAP is the most distinctive one. The protocol, has the ability of better and lighter performance in restricted resource networks and devices. There are a lot of implementations about COAP each has its own features and supplies. So, selecting the factors having effects on improvement of COAP protocol and also the implementation method suitable for the features of each of these supplies is important. So, optimal communication protocol which reduces traffic load is highly important and is now, of the main challenges in the IOT industry and smart houses which, in recent years, has attracted many researchers' attention. This study provides some features and an analytical comparison of many variables influencing the optimal performance of COAP. The present study has been conducted to answer the main question of the study: does the use of COAP have any effects on reducing energy consumption in the smart houses? The study has been conducted in the Uromieh Culture House and while studying the effective factors or important variables in improving the COAP performance, has tested the accuracy or inaccuracy of the hypotheses such as the main hypothesis of the study that there is a meaningful and positive relationship between using the COAP protocol and reducing energy consumption in organizations. Finally, a new approach will be introduced in this research causing improvement in the COAP efficiency. Then, its performance will be analyzed regarding reducing in energy consumption, delay in sending data, reducing memory and CPU consumption, the amount of information transmitted in each communication, firmness in failure and technological innovation. The present study aims at identifying the effect of using the COAP protocol on reducing energy consumption in the smart houses, Uromieh Culture House and ranking the factors influencing the implementation of performance improvement based on the smart houses. The paradigm of the present study is interpretive. In terms of purpose, the present study is of applied kind, in terms of data collection is of pluralistic one, in terms of procedure is of field and library one, in terms of data analysis method is a descriptive study and finally, in terms of time is a crosssectional one. The statistical sample of the present study's statistical society includes 49 people of the staff of the Uromieh Culture House who participate in the study as experts and professionals in IOT and new and emerging technologies of the smart houses fields. The results of data analysis show that the most effective factor in implementing the COAP protocol successfully on reducing energy consumption in the smart houses is to reduce energy consumption and the innovative technology factor has the least effect on successful implementation of the protocol.

Keywords-Smart house, reducing energy consumption, routing protocols in the IOT networks, constarined application protocol, COAP implementation, Fuzzy hierarchical analysis.

\section{INTRODUCTION}

$\mathrm{N}$ owadays, the present competitive environment, companies are wondering how to reduce their information Technology (IT) costs while increasing their efficiency and agility to react when changes in the business processes are required (Poorebrahimi \& SoleimaniRoozbahani,
2015), the information and communication technology ${ }^{1}$, has brought about great mutation and developments in different economical, technical and social parts of the people's lives in the developing countries (Ranjan, Somani, 2016) $)^{2}$ and it seems necessary for each

\footnotetext{
${ }^{1}$.Information communication technology (ICT)

${ }^{2}$ Ranjan, Somani
} 
organization to move towards process-focused that it is supported and presided by IT (Poorebarahimi, Razavi, \& SoleimaniRoozbahani, 2016). The IOT $^{3}$, in the meantime, is considered as a tremendous development of the technologies future technologies (Babovic, Protic\&Milutinovic, 2016) ${ }^{4}$ which can have an effect on all spectra of life and several businesses (Ali, 2016) ${ }^{5}$. One the efficient tools of the IOT is in the field of designing and implementing communication protocols (Iglesias, Orive\&Urbieta, 2017) ${ }^{6}$. In the meantime, $\operatorname{COAP}^{7}$ is among the known protocols in the IOT network which is used widely (Capossele, Cervo, De Cicco\&Petriol, 2015) ${ }^{8}$. Like other development tools, IOT, in the direction of information and communication technology needs to reinforce the factors that have a direct and meaningful relationship with its development (Granjal, Monteiro\& Silva, 2015) ${ }^{9}$. This technology, otherwise, like many other organizational procedures have no result than spending valuable time (Ali, 2016). In the developed communities, however, there is great enthusiasm among the researchers and experts of this technology because of plenty of benefits of the IOT (Samual, 2016) ${ }^{10}$. In different countries, there has been some research works in this regard (Chen, Kunz, 2016) ${ }^{11}$. Different studies including those conducted by the university of Massachusetts ${ }^{12}$ and Kevin Ashton ${ }^{13}$ (Saleem, Crespi\&Rehmani, 2017) ${ }^{14}$ which led to innovate the phrase "internet of things" as a complicated physical cyber system and the second internet (Yang, Wu, Yin \& Zhao,2017) ${ }^{15}$.

The things' internet or things net for which sometimes internet of things in used, was used originally by Kevin Ashton in 1999 (Yakubu, Adjei\&Babu , April, 2016) ${ }^{16}$ and described a world in which every thing like inanimate things have their own digital identity (Ancillotti, Raffaele Bruno, 2017) ${ }^{17}$ and organize and manage data transfer over network with no need for man to man or man to computer interaction by unique IDs and ability (Yi, Iwayemi\& Zhou, 2011) ${ }^{18}$. In a simple word, in IOT, sensors and devices are connected to networks that through which they can interact with each other and their users. This concept can be to the simple connection of a smart phone to a TV or the complicated monitoring urban infrastructure and traffic from washing machine and

\footnotetext{
${ }^{3}$ Internet on Things (IoT)

${ }^{4}$ Babovic, Protic\&Milutinovic

${ }^{5}$ Ali

${ }^{6}$ Iglesias, Orive\&Urbieta

${ }^{7}$ Constrained application protocol (COAP)

${ }^{8}$ Capossele, Cervo, De Cicco\&Petriol

${ }^{9}$ Granjal, Monteiro\& Silva

${ }^{10}$ Samual

${ }^{11}$ Chen. Kunz

12 university of Massachusetts Boston

${ }^{13}$ Kevin Ashton

${ }^{14}$ Saleem, Crespi\&Rehmani

${ }^{15}$ Yang, Wu, Yin \& Zhao

${ }^{16}$ Yakubu, Adjei\&Babu , April

${ }^{17}$ Ancillotti, Raffaele Bruno

${ }^{18} \mathrm{Yi}$, Iwayemi\& Zhou
}

refrigerator to the clothing we use (Pacheco, Gondim\&Barret, 2016) ${ }^{19}$. This network includes a lot of devices around us. Given the opinions of the scientists in this field and the research done, there will be about fifty to seventy five milliard IOT devices by 2020 (Navas, Lagos, Toutain\&Vijayasan, 2016) ${ }^{20}$. In Iran, however, significant efforts have been made to develop this technology; and it is necessary to make more efforts toward this technology. Considering this issue, the main purpose of research and its necessity is to implement an optimal protocol which reduces communication traffic congestion; and, since it is among the main challenges in the IOT industry which has attracted many researchers' attention, so the issue is highly important (Chavan, K.Nighot, 2016) ${ }^{21}$. The present study has presented features and an analytical comparison of several open source implementations of COAP. First, the present implementations are studied and then, they are compared in terms of internal structure, expandability, target platform, programming language and operational capability. Next, their performance will be analyzed in terms of delay time, memory and $\mathrm{CPU}^{22}$ consumption in the real test area used in a simulated scenario and some approaches will be suggested to improve the performance of the COAP protocol.

COAP is among the familiar protocols in the IOT network (Giang,Minkeun\&Daeyoung, 201) (23 $^{2}$ and is used widely (Skodzlk, 2015) ${ }^{24}$. COAP is a seven layer software protocol (applicationlayer) which is used in very simple electronics (Raza, Trabalza\& Voigt, 2013) ${ }^{25}$. This protocol allows an interactive relationship more than internet for these electronics (Ludovici ${ }^{26}, 2013$ ). The protocol is suitable for devices with constrained sources like $\mathrm{WSN}^{27}$ node, small and low power sensors, switches, valves and similar pieces which need remote control and/ remote monitoring such as standard internet networks (Shelby, Hartke\& Bormann, 2014) ${ }^{28}$

Hereof, in expressing the main issue of the research that is the use of COAP effective on reducing energy consumption in the smart houses (case study: Uromieh Culture House)? It has been tried to define the related concepts and their use. Then, the most important challenges in the Uromieh Culture House like lack of intelligence with the least energy consumption have been addressed among which the most important ones in this regard include the lack of intelligence in the Uromieh Culture House and the lack of devices that can be connected to each other through IOT and implement the intelligence issues with the least energy. So, the data and results collected from the Uromieh Culture House have

\footnotetext{
${ }^{19}$ Pacheco, Gondim\&Barret

${ }^{20}$ Navas, Lagos, Toutain\&Vijayasan

${ }^{21}$ Chavan, K.Nighot

${ }^{22}$ central processing unit (CPU)

${ }^{23}$ Giang,Minkeun\&Daeyoung

${ }^{24}$ Skodzlk

${ }^{25}$ Raza, Trabalza\& Voigt

${ }^{26}$ Ludovici

${ }^{27}$ Wireless Sensor Network (WSN)

${ }^{28}$ Shelby, Hartke\& Bormann
} 
been identified and summarized; additional suggestions also provided according to the results. In the following, the research limitations and some suggestions (tips) are also presented which can cause more and more growth for the COAP communication protocol in IOT as the final section of this study.

\section{THEORETICAL BASES}

\section{- IOT in the Smart houses}

Things internet or things net for which sometimes the phrase internet of things was first originally by Kevin Ashton in 1999 and described a world in which everything including inanimate things have their own digital identity and they can be organized and managed by unique IDs and ability to transfer data over network with no need for man to man or man to computer interaction. In simple words, the sensors and devices are connected to networks through which they can interact with each other and their users. This concept can be a simple connection of a smart phone with TV or the complexity of monitoring urban and traffic infrastructures from washing machine and refrigerator to our clothing; this network includes many devices around us. According to Evans and Chase, by 2020, there will be 50 milliard IOT devices; however, Jeon claims that the number will reach even to 75 milliard (Yakobo et al, 2016).

\section{- COAP protocol}

Constrained Application Protocol (COAP) is a software protocol used in very simple electrical devices and allows them interact with each other through internet. The constrained Restful environment (CoRE) work group belonging to the internet engineering task force did the main standardization work of the protocol. COAP is among the recommended protocols in the IOT network and is used widely. COAP is a seven layer (application layer) software protocol used in the very simple electronics. The protocol allows these devices to interact more than internet. The protocol is suitable for the internet devices with constrained sources like WSN node, small and low power sensors, switches, valves and similar pieces that need remote control/ monitoring such as standard internet networks. The traditional protocols used in traditional internet are not suitable for the constrained environment in which these tools can be found. The IETF workgroup, therefore, has standardized a protocol special for this environment called "constrained application protocol" (CoAP) by releasing RFC 725223 in 2014 (Ranjan, Somati, 2016).

CoAP has been made for the IOT devices to transmit files and data. This protocol uses the methods related to HTML language like GET, POST, PUT, DELETE for data transmission. In this way, there is no longer a difference between a sensor's access to the internet and a web application's access to information. Among the supportable connections in the operating system Mbed OS, connections IPv, Bluetooth, WiFi and G2 and G3 networks can be referred (Enslity, Rafael, 2017; Samuel, 2016).
WiFi is a known standard wireless communication and supports only Mbps bandwidth which is designed for a batch of communication protocols of higher level and is used with the help of small and low power digital radio to build personal wireless networks for uses like home automation, data collection of medical devices and other needs of low bandwidth for small scale projects which have no need for wireless communication (Chen, Kunz, 2016).

Chen, 2016: The four protocols MQTT ${ }^{29}$, CoAP, DDS and UDP (customized) are evaluated about their performance and compared by NetEM and TBF simulators. The result of this evaluation shows that DDS consumes more bandwidth than MQTT, (because of delay and reliability) is a right option to be applied in medical field (Chen. Kunz, 2016) ${ }^{30}$.

Ancillotti, Raffaele ${ }^{31}$, 2017: congestion control mechanisms in $\mathrm{CoCoA}+$ and CoAP protocols for different traffic patterns implemented based on scenario in real IOT environment has been analyzed completely. The results of this study indicates that $\mathrm{CoCoA}+$ can have a significantly worse performance than CoAP especially when traffic is strong and there are few clients and the time of resending packets in timeouts situation is not selected rightly. Moreover, it is difficult to make big changes in RTO values in CoCoA+ (Ancillotti, Raffaele, 2017).

\section{- An overview of the research background}

During past years, many efforts have been made to develop optimal communication protocols that in this section, techniques and approaches and a summary of background of the research done previously inside and outside the country about the topic of this research and their results will be reviewed and, finally a summarized table of the research will be provided.

CoAP has been so designed that include translated HTTP and plain integration with web easily and also specialty needs such as supporting multicast, low overhead and simplicity are included. Since in each network, efficiency has the first priority, CoAP can be implemented on most devices which support UDP or analogue UDP.

Multicast, low overhead and simplicity for IOT and machine to machine (M2M) is highly important. M2M are devices that have been designed depth oriented, have memory and the power supply in them is less than traditional internet devices. To make an appropriate protocol for IOT application and M2M, different features have been added to them. The kernel of this protocol is specified in RFC 7252; the important extension of different process steps is being standardized (Shelby ${ }^{32}$, 2014).

CoAP has been made for the IOT devices to transmit file and data. This protocol uses the methods related to HTML language including GET, POST, PUT, and DELETE. In this way, access to information of a sensor doesn't have

\footnotetext{
${ }^{29}$ Message Queue Telemetry Transport

${ }^{30}$ Chen. Kunz

${ }^{31}$ Ancillotti, Raffaele Bruno

${ }^{32}$ Shelby, Hartke\& Bormann
} 
much difference with access to information of a web based application. Among the supportable connections in the Mbed OS, the IPV ${ }^{33}$, IP, Blouetooth, WiFi, and G2 and G3 networks can be referred (Babovic et al, 2016) ${ }^{34}$.

Extensive evaluation based on real IOT systems shows that this architecture provides integration, privacy, affordable energy, end to end time interval, and memory overhead. To decrease the overhead when combining CoAP and DTLS, the header compression way with LOWPAN can be used. This protocol, also provides privacy communications for datagram protocols. The protocol is designed in a way that provides permissions to prevent eavesdropping, manipulating or forging massages for server and client applications. DTLS protocol is located in the transport layer security (TLS) ${ }^{35}$ protocol and this protocol provides equivalent security guarantees (Iglesias et al, 2017) $^{36}$. Since some of the IOT devices are placed in the environments in which power supply is not accessible, only have little energy to execute planed capabilities and heavy security instructions can discharge devices' sources (Yang et al, 2017) ${ }^{37}$. To decrease the severity of this issue, some possible methods can be used. First method is using minimum security requirements which is not particularly recommended when considering vital information. The second way is to increase battery capacity (Navas et al, 2016) ${ }^{38}$.

Most of the designed IOT devices, however, are lightweight and small. There is no extra for a big battery. The final approach is to supply energy from natural resources (like light, heat, vibration, wind). But this approach needs to promote to hardware and increases monetary costs considerably (Chavan, K. Nighot, 2016) ${ }^{39}$. Currently, there are many wireless IOT and non- IOT communication protocols and also wired non- IOT ones and considering the requirements, the most appropriate ones can be selected from among them. In this section, features, advantages and disadvantages of this protocol are studied. In comparison with wired technologies, the wireless ones, have better advantages like easy connection to unreachable areas or the areas with hard access and also have affordable infrastructures. The wireless technologies, however, because of the nature of the transfer path, may face signal weakening. On the other hand, the wired technologies don't have the problems of the wireless technologies like signal weakening and interference and unlike the wireless technologies, their performance is not dependent on battery. There are two kinds of information flows in the IOT devices. The first kind is among the smart devices and the IOT devices, sensors and home appliances and the second kind is among the smart devices and tools control centers. The first data flow can be run among the wireless connections like LowPAN, Zigbee and
Z- wave. The second data flow cab be run using cellular communications or through internet. There are several key constraining factors that should be considered in the process of establishing smart metering like operating costs, deployment time, technology accessibility and operational environment (including rural, urban, indoor and environment). Therefore, selecting the right technology for an environment may not applicable for another setting (Saleem et al, 2017) ${ }^{40}$.

Samuel $^{41}$, 2016: Z- Wave is a communication technology with low consumption IOT radio frequencies $(\mathrm{RF})^{42}$ that mainly is suitable for the smart houses. This device operates in $1 \mathrm{GHz}^{43}$ and provides a $100 \mathrm{~kb}$ data rate with a coverage area of 30 meters. Z- wave has been developed by Sigma Designs and uses the 128- bit encryption algorithm AES (Samuel, 2016).

Advantages: The main advantage of $\mathrm{Z}-\mathrm{Wave}$ is that $\mathrm{WiFi}$ and other wireless technologies operating in $2.4 \mathrm{GHz}$ have no collision like Zigbee and Bluetooth. This protocol has been optimized for reliable communications and short delay time in small data packets. This protocol is scalable and can control up to 232 devices. Also it can support Mesh networks without need for coordinator (Hug, Islam, 2010 $)^{44}$.

Advantages: of the features of LOWPAN is that it is suitable for the smart houses. This protocol has a very powerful communication model with very low battery consumption which can support a big Mesh topology. Moreover, considering the defined standard can be used in the physical layer and different frequencies and in several communication platforms (like IEEE 802.15.4, WiFi, Ethernet, and the band below $1 \mathrm{GHz}$ ) (Schroder, 2016) ${ }^{45}$.

Disadvantages: the main disadvantage of LOWPAN is that it needs extensive training to be able to operate with IPV protocol. Users couldn't implement this protocol easily, because they need to have wide knowledge about the IPV stack and its capabilities. In addition, one of its disadvantages is the same as that of $\mathrm{Z}$ - Wave. It means that it has been designed for small frames of the link layer, communication technology is done with low transfer speed; so, it is not suitable for medium and large networks (Schroder et al, 2016) ${ }^{46}$.

Schroder et al, 2016: LOWPAN protocol is a technology which has low battery consumption and covers a range wider than those protocols introduced so far. This protocol brings the capability of mobility, bidirectional secure communication and localization services and also interoperability. The data rate ranges from $0.3 \mathrm{kbps}$ to 50 kbps and the coverage ranges are from $2-5 \mathrm{~km}$ in urban environment and $15 \mathrm{~km}$ in suburb environment. The purpose of the most wireless communication designed technologies is to maximize the data transferred, but, they

\footnotetext{
${ }^{40}$ Saleem, Crespi\&Rehmani

${ }^{41}$ Samuel

${ }^{42}$ Radio Frequency

${ }^{43}$ Gigahertz

${ }^{44}$ Hug, Islam

${ }^{45}$ Schroder Filho, PissolatoFilho\& More

${ }^{46}$ Schroder Filho, PissolatoFilho\& More
} 
mainly cover low battery consumption and long range communication (which causes reduction in the maximum transferred data). Moreover, the server of the LoRaWan network manages the RF output rate and data rate for each IOT device by the way of adaptation data rate (ADR) to increase network capability and the battery life of each IOT device. This protocol covers a wide spectrum of bands which has no interference in different data rates during communications. Furthermore, it creates some virtual channels which increase the capability of gates (Schroder et el, 2016).

\section{The Conceptual Model OF THE RESEARCH}

After reviewing the research records, it was found that in this protocol, performance improvement can be divided into an independent variable and the following main sections. And, under the influence of the components, the following dependent variable can be considered. All of these variables, somehow, influence each other and reducing energy consumption and ultimately, lead to improvement of the CoAP performance. The components influencing the improvement of the CoAP performance are studied in this research as following: 1- reducing energy consumption, 2 - latency ${ }^{47}$ time in sending data, 3- memory and CPU consumption, 4- the amount of information transmitted per connection, 5- firmness against failure, 6technological innovation. Considering the introduced variables, the following figure was developed as the conceptual model of the research which considers the concept of performance improvement in the CoAP protocol given the factors influencing it. In figure (1) the aspects of the mentioned model is shown. In the following conceptual model, the component of reducing energy consumption is the dependent variable which itself, influences the components of memory and CPU consumption and also latency in data sending. In the present research, it has been tried to evaluate the effect of improving the CoAP protocol which includes the parameters of technological innovation, firmness against failure and the amount of data sent per connection, on the quality of latency in data sending and reducing the consumed memory and CPU, that, the positive and direct effect of these components on each other leads to reduction in energy consumption and finally improvement in the CoAP protocol's performance.

But this part of the research (focusing on reduction in energy consumption, latency in data sending, the amount of information sent per connection and memory consumption, firmness against failure and innovation in this field) receive little attention. The innovation of this research relative to its previous histories is the topics mentioned above, which some comprehensive research works have been conducted in questionnaire form from the experts and workers of the Uromieh Culture House which their results are expressed in the analysis of information

\footnotetext{
${ }^{47}$ latency
}

and also in the conceptual model from the variables and their effects on the main category of the research.

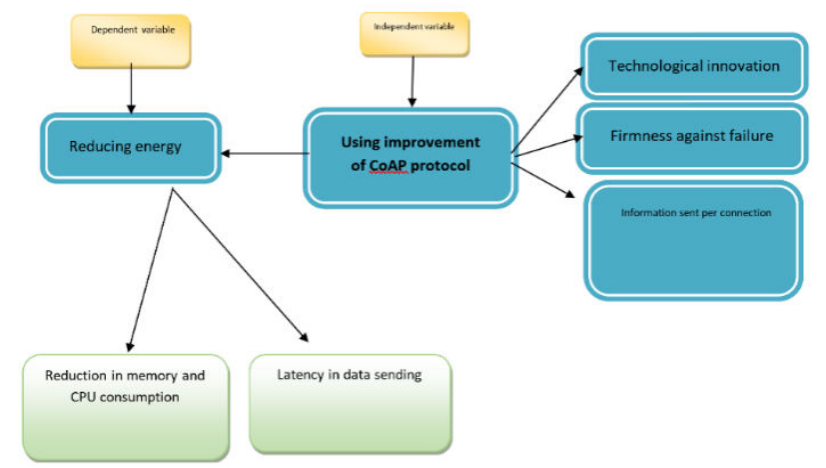

Figure (1): the conceptual model of the research

\section{CONCEPTS AND APPROACHES}

The evolution and development of the technologies along with its globalization have made new opportunities which increased at the same time, new challenges. This issue, makes reviewing and studying the executive and practical practices necessary.

1) Concepts (the features and factors influencing the implementation of CoAP protocol)

The component of reducing energy consumption has the most effect on improving the CoAP protocol, considering this important issue that reduction in energy consumption is very fruitful economically and in terms of optimal organizational management. The key for energy efficiency, on the other hand, is management. So, it is appropriate to manage all energy sources and consumption towards efficiency to prevent consumption resources of the organization's system (consumption resources like memory and CPU) from wasting. Certainly, reduction in the costs of energy consumption in organizations is directly related to increase in value added. In the service organizations such as the culture houses, energy efficiency means the maximum use of the consumable resources that, in this case, most energy saving activities reflect on the consumable resources of memory and CPU.

\section{LATENCY IN DATA TRANSMISSION}

Data transmission among nodes in the smart house is highly important. So, the less the data transmission is delayed, the better and more optimal the data will be processed.

\section{- Memory and CPU consumption}

Since the amount of resource used in the smart house's nodes is limited, it is suitable, therefore to make the possibility of use the least memory and CPU by managing resources for sending, receiving and processing data correctly.

\section{- $\quad$ The amount of information transmitted per connection}

The average size of the transmitted data is among the whole nodes in the smart houses which is very important. This component can serve as a regulator of the variables of reducing energy consumption, latency in data transmission 
and memory and CPU consumption by increasing data transmission.

\section{- Firmness against failure}

The organizational and servicing environments with the help of ICT, try to develop a new system by reducing energy consumption or cutting back premium service costs. Naturally, therefore, it is highly probable for their efforts to failure. In addition, the process of creating IOT requires some tests that finally lead to success. In this process, naturally, there are some failures and obstacles. Ability to endure against the failure and obstacles is an experiment and benchmark.

\section{TECHNOLOGICAL INNOVATION}

Accepting the issue of innovation in ICT that unpredictable conditions can disturb the IOT- based service plans, will bring the abilities of a desired intelligent and alert technology leading to success. The ability to make a new idea in business successfully like servicing in the culture house or any organization via reducing the energy consumption means to create a new model, a new work team, profitability, participation, energy consumption resources management, financial resources, leadership, motivating employees and so on. Many innovations enable innovational activities to run smoother and more effective.

\section{RESEARCH METHOD}

The purpose of the present study was to identify and classify the factors having impact on using the CoAP protocol in reducing energy consumption in the smart houses in the Uromieh Culture House with the subject of managing the nodes extant in the smart houses. The present study has a descriptive paradigm. In terms of the purpose and result, the present study is of applied kind, and taking the nature of the present research and the targeted statistical society, data collection methods and procedure in to consideration, it is of library and filed kind. In terms of the data analysis methods, it is descriptive and finally, in terms of time, it is a cross sectional study. The participators in this research, include the experts and professional in the field of emerging technologies sciences and IT who have at least 5 years of scientific and practical experiences. The research data were analyzed by Fuzzy hierarchical analysis; variables were reckoned and a questionnaire was compiles and distributed to the experts. In this research, the SPSS statistical software and Kolmogorov and Smirnov tests were used to analyze data that finally, the available statistical analyses were calculated by Alpha Cronbach and since its values were higher than 0.7, indicated the right reliability of the used tools. The statistical sample from the statistical society of the present research includes 49 people from the Uromieh Culture House staff who are as the participators in this research, the experts and professionals of the IOT field and emerging and novel technologies of the smart houses' field and the expert staff of the Uromieh Culture House. According to the questionnaire distribution, the research was conducted in the spring of 2018. In this research the validity has been extract through interview with the specialist professors of this field and the experts. To calculate the Alpha Cronbach's coefficient, the variance of the questionnaire's scores and totalvariance was first calculated which finally the present statistical analyses were calculated by Alpha Cronbach. And since its value was higher than 0.7, indicated the right reliability of the used tools. Also, according to the research results, the most important priority in classifying the factors effective on improving the CoAP protocol wasdetermined and dedicated ranks of 1 to 6 to its own.

Table (1) Cronbach's Alpha Test results

\begin{tabular}{|l|c|}
\hline \multicolumn{1}{|c|}{ Variables } & $\begin{array}{c}\text { Alpha } \\
\text { Cronbach's } \\
\text { Coefficient }\end{array}$ \\
\hline Firmness against failure & 0.784 \\
\hline $\begin{array}{l}\text { Amount of information } \\
\text { transmitted per connection }\end{array}$ & 0.815 \\
\hline $\begin{array}{l}\text { Focus on reducing the energy } \\
\text { consumption }\end{array}$ & 0.915 \\
\hline Memory and CPU consumption & 0.819 \\
\hline Latency in data transmission & 0.906 \\
\hline Technological innovation & 0.781 \\
\hline
\end{tabular}

\section{FINDINGS}

After explaining the research method and the data collection method, the number of the experts ready to responsiveness and cooperation was determined and the questionnaires with questions about the related variables and having the research questions and hypotheses provided in table (5) were distributed among the experts and professionals. In this research, conducted in the Uromeih Culture House, the staff of this statistical society is 49 persons. And, finally the general average of indices is as follows:

$96 \%$ of respondents are men and $4 \%$ women. $20 \%$ of the respondents have a master's degree and higher, $80 \%$ are B.A and no one have associate degree. $12 \%$ of the respondents have more than 16 years of work experience, $73 \%$ of them have between 11- 15 years of work experience, $12 \%$ have 10 years work experience and $2 \%$ have less than 5 years of work experience. $30 \%$ of the respondents are 51 years old and higher, $38 \%$ are between $41-50$ years old, $29 \%$ have $31-40$ ages and $2 \%$ have 20 30 ages. The position of the research indictors and general information obtained in this regard are shown in the table (4), general position of indicators.

The data collected were analyzed in two parts of descriptive and inferential statistics. In the descriptive statistics, the data process, frequency, percentage and mean were studied, which were used in this research to analyze the data and information statistically and display them graphically in tables and frequency chart and SPSS software.

In the inferential statistics, the relationships among the variables and in fact, the research hypotheses were tested statistically. In this research, the data collected first was 
summarized and classified using the descriptive statistics indicators, then, the Fuzzy AHP and the inferential statistics tests including structural equation modeling were used to prioritize and weight the research components. The Fuzzy AHP and FUZZY TOPSIS were used to weight and prioritize the targeted research components. The weight of criteria, first calculated by the AHP method and these weights, then, were used in the TOPSIS manner to rank options according to table (8) and diagram (1). As the results in table (8) show, the components:1- focus on reducing energy consumption, 2- latency in data transmission, 3- memory and CPU consumption, 4- the information transmitted per connection, 5- firmness against failure, and 6- technological innovation dedicated 1-6 ranks to themselves respectively.

The research data were analyzed by the Fuzzy hierarchical analysis. Finally, reliability and validity and also Alpha Cronbach's coefficient were created for each variable. The Alpha Cronbach's coefficient was obtained higher than 0.7 and the questionnaire's reliability were evaluated as appropriate. The analysis of the general position of the indicators is shown in table (2).

Table (2). General position of indicators

\begin{tabular}{|l|l|l|l|}
\hline Component & Frequency & Mean & SD \\
\hline $\begin{array}{l}\text { Information size } \\
\text { transmitted per } \\
\text { connection }\end{array}$ & 49 & 3.3467 & 0.089422647 \\
\hline $\begin{array}{l}\text { Memory and } \\
\text { CPU } \\
\text { consumption }\end{array}$ & 49 & 3.2894 & 0.074226 \\
\hline $\begin{array}{l}\text { Latency in data } \\
\text { transmission }\end{array}$ & 49 & 3.4210 & 0.087160333 \\
\hline $\begin{array}{l}\text { Firmness against } \\
\text { failure }\end{array}$ & 49 & 3.0614 & 0.061553 \\
\hline $\begin{array}{l}\text { Reducing the } \\
\text { energy } \\
\text { consumption }\end{array}$ & 49 & 3.1754 & 0.054195333 \\
\hline $\begin{array}{l}\text { Technological } \\
\text { innovation }\end{array}$ & 49 & 3.2982 & 0.061088333 \\
\hline
\end{tabular}

The questionnaires used in this study were designed based on index evaluation and their estimate way, which these indices were extracted according to studying theoretical bases, examination of different work samples, and interviewing with several groups.

Given the literature and the paper reviewed above about the questions posed in the research and the research main hypothesis based on the effect of using the CoAP protocol on reducing the energy consumption in the smart houses, reducing the energy consumption, latency in data transmission, memory and CPU consumption, information transmitted per connection, firmness against failure and technological innovation. Also, each of the factors was classified, identifying the effective factors to answer the research questions. The most effective factors of using the CoAP protocol on reducing the energy consumption in the smart houses is reducing energy consumption and the technological innovation factor has the least effect on the successful implementation of the CoAP protocol.
Considering the questions posed in the answer sheet distributed to the experts and professionals and after analyzing the resulting data and the summary of results, all the research questions and hypotheses were answered appropriately.

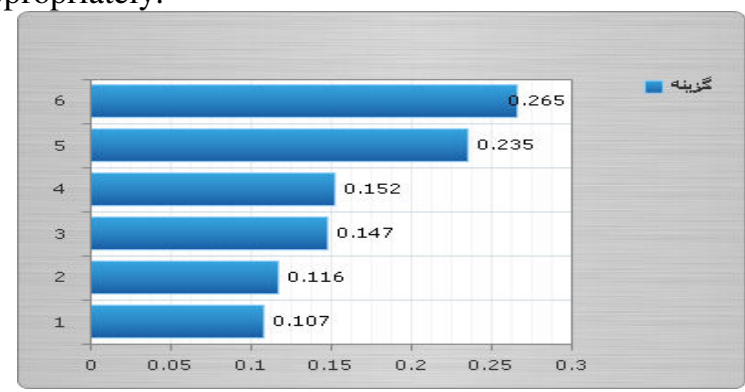

Diagram (1) final values of options relative to the purpose (classification of each factor influencing the improvement of the CoAP's performance)

As the results show: 1- focus on reducing the energy consumption, 2- latency in data transmission, 3- memory and CPU consumption, 4- the size of information transmitted per connection, 5- firmness against failure, and 6- technological innovation were ranked 1 - 6 respectively.

1 - Is it possible to reduce the energy consumption and create communication disorders like few missed packets by the possibility of reducing the latency variable?

Considering the data analyses from the field and library studies, it is concluded that according to table (9), there is a positive relationship between the latency in data transmission and reducing the energy consumption. As it can be seen, the Spearman amount and the significance level indicate that there is a positive significant relationship between latency in data transmission and reducing the energy consumption leading to fixing communication disorders like the missed packets. The data transmission among the nodes in the smart houses is very important. So, the less time the data is transmitted, the better the processes in the smart house will be done.

2- What is the effect of the variables dependent upon the technological innovation variable on improving the performance of the CoAP protocol?

Accepting the issue of innovation in ICT that the unpredictable conditions can disturb the IOT- based service applications, will bring some intelligent and vigilant desired technologies causing success. The ability to successfully give effect to a new idea in business like servicing in the smart house or any other organization by reducing the energy consumption means to create a new model, create a new working team, profitability, participation, management of energy resource consumption, funds, leadership and motivating the personnel and so on. Many innovations enable the innovational activities to run smoother and more effective and finally with less energy consumption.

Proof of the research hypotheses in findings with the help of data analyses from the research 


\section{MAIN HYPOTHESES}

There is positive and meaningful relationship between using the improved CoAP protocol and reducing the energy consumption:

Table (10) shows the relationship between reducing the energy consumption and improved CoAP protocol. As can be seen, the Spearman coefficient and significance level indicate a positive and meaningful relationship between the two variables improved the CoAP protocol and reducing energy consumption.

Table (3) shows the summary of results of confirmation or disapproval of the research hypotheses (reference: results of research method analysis).

Table (3). The summary of results of confirmation or disapproval of the research hypotheses

\begin{tabular}{|c|c|c|c|}
\hline NO. & Hypotheses & Confirmed & Disapproved \\
\hline 1 & $\begin{array}{l}\text { Main hypotheses } \\
\text { (there is a positive } \\
\text { and significant } \\
\text { relationship } \\
\text { between using the } \\
\text { improved CoAP } \\
\text { and reduction in } \\
\text { energy } \\
\text { consumption in the } \\
\text { organization). }\end{array}$ & $\checkmark$ & \\
\hline 2 & $\begin{array}{l}\text { Secondary } \\
\text { hypothesis 1-there } \\
\text { is a significant } \\
\text { relationship } \\
\text { between } \\
\text { technological } \\
\text { innovation and } \\
\text { reducing the } \\
\text { energy } \\
\text { consumption. }\end{array}$ & $\checkmark$ & \\
\hline 3 & $\begin{array}{l}\text { Secondary } \\
\text { hypothesis 2- there } \\
\text { is a meaningful } \\
\text { relationship } \\
\text { between } \\
\text { firmness against } \\
\text { failure the } \\
\text { reducing and } \\
\text { energy } \\
\text { consumption. }\end{array}$ & $\checkmark$ & \\
\hline 4 & $\begin{array}{l}\text { Secondary } \\
\text { hypothesis } 3 \text { - there } \\
\text { is a meaningful } \\
\text { relationship } \\
\text { between the size of } \\
\text { information } \\
\text { transmitted per } \\
\text { connection and } \\
\text { reduction } \\
\text { energy } \\
\text { consumption. }\end{array}$ & $\checkmark$ & \\
\hline
\end{tabular}

Considering the data resulting from analyzing the collected questionnaires, the resulting technique diagram is as follows:

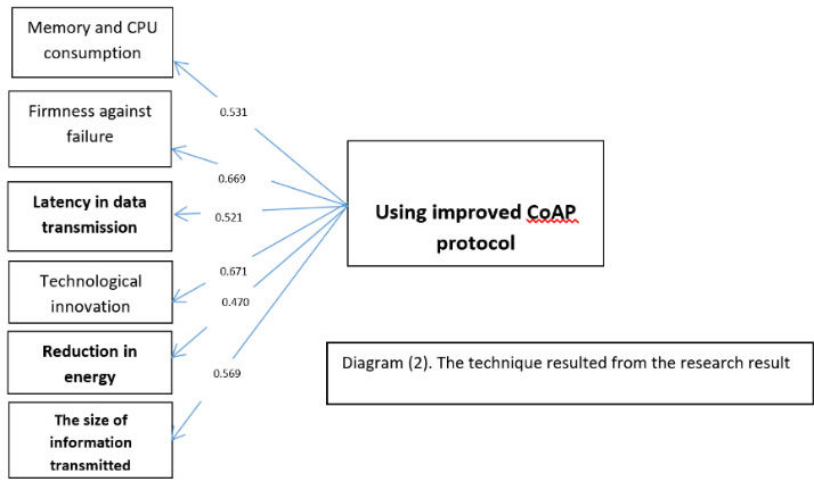

\section{Conclusion}

The research results show that according to the research results, the most important priorities in classification of the effective factors on improved CoAP protocol and the effect of using CoAP on reducing energy consumption in the smart houses are considered as reduction in energy consumption, latency in data transmission, memory and CPU consumption, the size of information transmitted per connection, firmness against failure and technological innovation respectively and are ranked from 1 to 6 . The most important factor in the effect of using the CoAP protocol on reducing the energy consumption is to reduce the consumable energy and technological innovation is the least effective on improved performance and successful implementation of the CoAP protocol. The innovations enable the innovational activities work more efficiently by reducing the energy consumption. The less time the data transmission is delayed, the better and more efficient the processes in the smart houses will be done. The validity test of the main hypothesis (the positive and significant relationship between focus on reducing the energy consumption and improved performance of CoAP)) and the secondary hypotheses of the research (the mutually meaningful relationship between the technological innovation and reducing the energy consumption, the relationship between the firmness against failure and reduction in energy consumption and also the positive and significant relationship between the amount of information transmitted per connection and reduction in the energy consumption) were confirmed.

Finally, it is suggested to consider the improved performance not only as an ICT tool in the organization, but as a new architecture in the organizational progression system. Moreover, you should be careful that the effectiveness of these components on the improved performance of the CoAP, need to both specific infrastructure and special and professional users. And, the success in the IT and IOT field will be realized if the perquisite is prepared to implement it. Taking the importance of the issue into consideration, it is necessary to make some suggestions for future research: 
Proposals:

1- To study and analyze the effects of IT and improved performance of the CoAP on the function field in the organizations' servicing system.

2- To analyze and prioritize the effects of organizational investment on implementation of the improved CoAP protocol

3- To study the effects of the improved CoAP protocol on improving service performance in the organizations

\section{REFERENCES}

1. Babovic, Protic \& Milutinovic,, Z. (2016). "Web Performance Evaluation for Internet of Things Applications,". in IEEE Access, 4, 6974-6992.

2. Chen. Kunz, Y. (2016). "Performance evaluation of IoT protocols under a constrained wireless access network,". 2016 International Conference on Selected Topics in Mobile \& Wireless Networking (MoWNeT), Cairo.

3. Giang,Minkeun \& Daeyoung, N. (2013). "SCoAP: An integration of CoAP protocol with web-based application." GLOBECOM.

4. Granjal, Monteiro \& Silva, J. (2015). "Security for the Internet of Things: A Survey of Existing Protocols and Open Research Issues,". in IEEE Communications Surveys \& Tutorials pp, 17(3), 1294-1312.

5. Huq , Islam,, M. (2010). "Home area network technology assessment for demand response in smart grid environment,". in Universities Power Engineering Conference (AUPEC), 2010 20th Australasian. IEEE.

6. Konieczek, Rethfeldt \& Golatowski , B. (2015). "RealTime Communication for the Internet of Things Using jCoAP,". 2015 IEEE 18th International Symposium on Real-Time Distributed Computing, Auckland.

7. Kuzlu, Pipattanasomporn \& Rahman, M. (2015). "Review of Communication Technologies for Smart Homes/Building Applications,". in IEEE Innovative Smart Grid Technologies-Asia (ISGT ASIA).

8. Lewis, Igic \& Zhou, R. (2009). "Assessment of Communication Methods for Smart Electricity Metering in the UK. in IEEE PES/IAS Conference on Sustainable Alternative Energy (SAE).

9. Montenegro,Kushalnagar, Hui \& Cull, G. (2007). "Transmissionof IPv6 Packets over IEEE 802.15.4 Networks," Internet Requests for Comments, IETF, RFC 4944. [Online]. Retrieved from Available: http://www.rfceditor.org/rfc/rfc4944.txt.

10.Navas, Lagos, Toutain \& Vijayasan, R. (2016). "Nonce-based authenticated key establishment over OAuth 2.0 IoT proof-of-possession architecture,". 2016
IEEE 3rd World Forum on Internet of Things (WF-IoT), Reston, VA.

11.Raza, Trabalza \& Voigt, S. (2013). "6LoWPAN Compressed DTLS for CoAP,". 2012 IEEE 8th International Conference on Distributed Computing in Sensor Systems, Hangzhou.

12.Rescorla, Modadugu, , E. (2006). DTLS: Datagram Transport Layer Security, RFC 4347.

13.Saleem, Crespi \& Rehmani, Y. (2017). "Internet of Things-aided Smart Grid: Technologies, Architectures, Applications, Prototypes, and Future Research Directions" ArXiv.

14.Schroder Filho, Pissolato Filho \& More, H. (2016). "The Adequacy of LoRaWAN on Smart Grids: A Comparison with RF Mesh Technology,". in IEEE International Smart Cities Conference (ISC2).

15.Shelby, Hartke \& Bormann,, Z. (2014). "RFC 7252: The Constrained Application Protocol (CoAP).".

16.Yang, Wu, Yin \& Zhao, Y. (2017). "A Survey on Security and Privacy Issues in Internet-of-Things,". in IEEE Internet of Things Journal, 99.

17.Yi, Iwayemi \& Zhou, P. (2011). "Developing ZigBee Deployment Guideline under WiFi Interference for Smart Grid Applications,”. IEEE Transactions on Smart Grid, 2(1), 110-120.

18."Evaluation of Distributed Denial of Service threat in the Internet of Things,"2016 2016 IEEE 15th International Symposium on Network Computing and Applications (NCA), Cambridge, MA

19.Ancillotti, Raffaele Bruno. (2017). "Comparison of $\mathrm{CoAP}$ and $\mathrm{CoCoA}+$ Congestion Control Mechanisms for Different IoT Application Scenarios". 22nd IEEE Symposium on Computers and Communications.

20.Capossele, Cervo, De Cicco \& Petriol, A. (2015). "Security as a CoAP resource: An optimized DTLS implementation for the IoT,". 2015 IEEE International Conference on Communications (ICC), London.

21.Chavan, K.Nighot, A. (2016). "Secure and Costeffective Application Layer Protocol with Authentication Interoperability for IOT"'.

22.I.Ali. (2016). "Internet of Things Security, Device Authentication and Access Control: A Review". (IJCSIS) International Journal of Computer Science and Information Security.

23.Iglesias, Orive \& Urbieta, M. (2017). "Analysis of CoAP Implementations for Industrial Internet of Things: A Survey". 109. 
24.IOT. (2016). Internet of Things (IoT) Protocols You Need to Know About," accessed: September. Retrieved from [Online]. Available: http://www.rsonline.com/designspark/electronics/knowledgeitem/eleven-internet-of-things-iot-protocols-you-need-toknow-about.

25.KuladinithI, Koojana, Bergmann \& Pötsch . (2011). "Implementation of CoAP and its Application in Transport Logistics."

26.Ludovici, A. (2013). "TinyCoAP: A Novel Constrained Application Protocol (CoAP) Implementation for Embedding RESTful Web Services in Wireless Sensor Networks Based on TinyOS", Journal of Sensor and Actuator Networks.

27.Ludovici, Calveras, A. (2015). "A Proxy Design to Leverage the Interconnection of CoAP Wireless Sensor Networks with Web Applications", sensors, ISSN. 14248220 .

28.Pawlowski, Jara \& Ogorzalek, M. (2015). Compact Extensible Authentication Protocol for the Internet of Things. Enabling Scalable and Efficient Security Commissioning. Mobile Information Systems .

29.Petajajarvi, Mikhaylov, Roivainen \& Han, J. (2015). "On the Coverage of LPWANs: Range Evaluation and Channel Attenuation Model for LoRa Technology,". in 14th International Con-ference on ITS Telecommunications (ITST).

30.Poorebarahimi, A., Razavi, F., \& SoleimaniRoozbahani, F. (2016). Presenting VALIT Frameworks and Comparing between Them and Other Enterprise Architecture Framework. Int. J. Advanced Networking and Applications , 7(4), 2805-2809.

31.Poorebrahimi, A., \& SoleimaniRoozbahani, F. (2015). Effects of Security and Privacy Concerns on using of Cloud Services in Energy Industry, an Oil and Gas Company: A Case Study. Int. J. Advanced Networking and Applications , 2779-2783.

32.Ranjan, Somani , A. (2016). Access Control and Authentication in the Internet of Things Environment. In: Mahmood Z. (eds) Connectivity Frameworks for Smart Devices. Computer Communications and Networks. Springer, Cham.

33.Samuel, S. (2016). "A Review of Connectivity Challenges in IoT-Smart Home,". in 3rd MEC International Conference on Big Data and Smart City (ICBDSC).

34.Skodzlk, J. (2015). "CoHaRT: A P2P-based deterministic transmission of large data amounts using CoAP,". 2015 IEEE International Conference on Industrial Technology (ICIT), Seville.
35.Yakubu, Adjei \& Babu, O. (April 2016). A Review of Prospects and Challenges of Internet of Things. International Journal of Computer Applications, 139(10), 33-39. 